\title{
Urocortin protects chondrocytes from NO-induced apoptosis: a future therapy for osteoarthritis?
}

\author{
NY Intekhab-Alam ${ }^{1}$, OB White ${ }^{1}$, SJ Getting ${ }^{2}$, A Petsa ${ }^{1}$, RA Knight ${ }^{3}$, HS Chowdrey ${ }^{1}$, PA Townsend ${ }^{4}$, KM Lawrence ${ }^{4}$ and IC Locke ${ }^{*, 1}$
}

Osteoarthritis $(\mathrm{OA})$ is characterized by a loss of joint mobility and pain resulting from progressive destruction and loss of articular cartilage secondary to chondrocyte death and/ or senescence. Certain stimuli including nitric oxide (NO) and the proinflammatory cytokine tumor necrosis factor $\alpha$ (TNF- $\alpha$ have been implicated in this chondrocyte death and the subsequent accelerated damage to cartilage. In this study, we demonstrate that a corticotrophin releasing factor (CRF) family peptide, urocortin (Ucn), is produced by a human chondrocyte cell line, C-20/A4, and acts both as an endogenous survival signal and as a cytoprotective agent reducing the induction of apoptosis by NO but not TNF- $\alpha$ when added exogenously. Furthermore, treatment with the NO donor S-nitroso- $N$-acetyl-D-L-penicillamine upregulates chondrocyte Ucn expression, whereas treatment with TNF- $\alpha$ does not. The chondroprotective effects of Ucn are abolished by both specific ligand depletion (with an anti-Ucn antibody) and by CRF receptor blockade with the pan-CRFR antagonist $\alpha$-helical $\mathrm{CRH}_{(9-41)}$. CRFR expression was confirmed by reverse transcription-PCR with subsequent amplicon sequence analysis and demonstrates that C-20/A4 cells express both CRFR1 and CRFR2, specifically CRFR1 $\alpha$ and CRFR2 $\beta$. Protein expression of these receptors was confirmed by western blotting. The presence of both Ucn and its receptors in these cells, coupled with the induction of Ucn by NO, suggests the existence of an endogenous autocrine/paracrine chondroprotective mechanism against stimuli inducing chondrocyte apoptosis via the intrinsic/mitochondrial pathway.

Cell Death and Disease (2013) 4, e717; doi:10.1038/cddis.2013.231; published online 11 July 2013

Subject Category: Experimental Medicine

Articular cartilage of the joints forms a smooth, shockabsorbing surface covering opposing subchondral bone and is essential for the normal function of the joint. ${ }^{1}$ This connective tissue is produced by only one type of specialized cell, the chondrocyte. The extracellular matrix produced and recycled by these cells is rich in collagen fibers embedded in proteoglycans and provides high mechanical strength. These cells are therefore crucial for normal joint integrity. ${ }^{2,3}$ During the aging process and in pathologies of the aged, such as osteoarthritis (OA), there is a loss of joint mobility and pain especially in the knees, hips, hands and vertebrae. In OA, these changes have been attributed to a reduction in the number of active chondrocytes in articular cartilage, occurring primarily in the superficial zone of the cartilage without distinct changes in the middle or deep zones ${ }^{4}$ and the severity of cartilage damage correlates very closely with the number of remaining active cells. ${ }^{4,5}$ In these conditions, chondrocyte death appears to be essentially apoptotic, but with subtle differences, for example, membrane 'blebbing' is rarely seen. This has led to the phrase 'chondroptosis' being suggested to describe the unique form of apoptosis/programmed cell death observed in these cells. ${ }^{6}$

Although it has now become established that chondrocyte cell death contributes to progressive articular cartilage damage and a loss of joint function, the stimuli involved are unclear. Several locally occurring factors have, however, been implicated including nitric oxide (NO), ${ }^{7}$ oxygen-free radicals, ${ }^{7}$ tumor necrosis factor $\alpha(\mathrm{TNF}-\alpha),{ }^{8}$ interleukin $1 \beta(\mathrm{IL}-1 \beta)^{9}$ and Fas ligand. ${ }^{10}$ The effects of these stimuli on chondrocytes have been shown to contribute to accelerated damage of articular cartilage in vivo. ${ }^{3}$ Of these, $\mathrm{NO}$ and the pro-inflammatory cytokines TNF- $\alpha$ and IL- $1 \beta$ are likely to be significant contributors to the apparent changes in chondrocyte function and viability observed during cartilage degradation. NO, in particular, is present in significant quantities within $\mathrm{OA}$ joints in vivo ${ }^{11}$ and elevated levels of $\mathrm{NO}$ in the cartilage and synovial fluid may be a result of excess production in response to a variety of mechanical and chemical stresses. These increased levels of NO may be a result of the action of a neuronal NO synthetase-like enzyme,

\footnotetext{
${ }^{1}$ Department of Biomedical Sciences, School of Life Sciences, University of Westminster, 115 New Cavendish Street, London W1W 6UW, UK; ${ }^{2}$ Department of Human and Health Sciences, School of Life Sciences, University of Westminster, 115 New Cavendish Street, London W1W 6UW, UK; ${ }^{3}$ Medical Molecular Biology Unit, University College London, Rayne Building, 5 University Street, London WC1E 6JF, UK and ${ }^{4}$ Faculty Institute for Cancer Sciences, University of Manchester, Manchester Academic Health Science Centre, St Mary's Hospital, Oxford Road, Manchester M13 9WL, UK

*Corresponding author: IC Locke, Department of Biomedical Sciences, School of Life Sciences, University of Westminster, 115 New Cavendish Street, London W1W 6UW, UK. Tel: +44 2079115000 x.64151; Fax: +44 20 7911 5087; E-mail: i.c.locke@ wmin.ac.uk

Keywords: chondrocyte; apoptosis; nitric oxide; urocortin

Abbreviations: NO, nitric oxide; OA, osteoarthritis; TNF- $\alpha$, tumor necrosis factor- $\alpha$; CRF, corticotrophin releasing factor; Ucn, urocortin; SNAP, S-nitroso- $N$-Acetyl-D,Lpenicillamine; CRFR, corticotrophin releasing factor receptor; RT-PCR, reverse transcription-PCR; IL-1 $\beta$, interleukin $1 \beta$; nNOS, neuronal nitric oxide synthetase; CRF-BP, corticotrophin releasing factor-binding protein; TUNEL, terminal deoxynucleotidyl transferase dUTP nick end labeling; LDH, lactate dehydrogenase; GAPDH, glyceraldehyde 3-phosphate dehydrogenase; DMEM, Dulbecco's modified Eagle's medium; FCS, fetal calf serum; Tris, tris(hydroxymethyl)aminomethane Received 12.2.13; revised 07.5.13; accepted 08.5.13; Edited by A Stephanou
} 
which has been detected in OA cartilage but not in normal articular cartilage. $^{12} \mathrm{NO}$ may also mediate cartilage matrix loss by upregulation of matrix metalloproteinases (MMP-9 and MMP-3) causing further degradation of the cartilage matrix. ${ }^{13}$ It has also been shown in vitro that the addition of a NOS inhibitor can reduce the level of observed apoptotic cell death. ${ }^{14}$ Certain experimental models of $\mathrm{OA}$ in various species also indicate a correlation between the level of $\mathrm{NO}$ production and prevalence of apoptotic cells in cartilage tissue. ${ }^{15}$ It is clear that imbalances in cartilage homeostasis observed in both $\mathrm{OA}$ and the aging process need to be redressed and that key to this is the protection of chondrocytes from apoptotic death.

Recently, the neuropeptide urocortin (Ucn) has been found to be elevated in the synovial fluid of patients with rheumatoid arthritis. ${ }^{16}$ It also reduces inflammation and bone erosion in a mouse model of the disease. ${ }^{17}$ Beyond this, little is known of the role of Ucn in the pathobiology of OA. This small peptide and its paralogs Ucnll (human stresscopin-related peptide) and UcnIII (human stresscopin) are members of the corticotrophin releasing factor (CRF) family. These peptides have been demonstrated to have pleiotrophic effects on numerous cell systems including anti-apoptotic actions in heart ${ }^{18}$ and the regulation of skeletal osteoclast differentiation and resorption, ${ }^{19}$ acting in an autocrine or paracrine manner. ${ }^{20}$ These agonists bind to two classes of receptor CRF receptor 1 (CRFR1) and CRFR2 (which are expressed as multiple isoforms due to alternate RNA splicing ${ }^{21}$ ). Signaling complexity is increased further by receptor promiscuity, enabling the activation of different $G$ proteins by the same receptor subtype. $^{22}$ Studies have demonstrated that Ucn can bind to both CRFR1 and CRFR2, whereas Ucn II and Ucn III bind exclusively to CRFR2. ${ }^{23}$ The system is completed by a highaffinity binding protein (CRF-BP), which acts as a decoy receptor and regulates functional peptide availability. ${ }^{24}$

Here we report that $U c n$ is expressed in the chondrocyte cell line C-20/A4, and that this cell line expresses both CRFR1 and $\mathrm{R} 2$ receptor subtypes. Furthermore, Ucn is essential for C-20/A4 cell survival, and is also a potent chondroprotective agent against cell death induced by pro-apoptotic stimuli.

\section{Results}

The effects of pro-apoptotic stimuli on C-20/A4 chondrocytes. C-20/A4 cell death was analyzed in the presence of ascending concentrations of the pro-apoptotic stimuli S-nitroso- $N$-acetyl-D-L-penicillamine (SNAP), a nitric oxide (NO) donor and TNF- $\alpha$. C-20/A4 cultures were analyzed for apoptotic cell death by Annexin $\mathrm{V}$ and terminal deoxynucleotidyl transferase dUTP nick end labeling (TUNEL) assays with the use of cytoplasmic lactate dehydrogenase (LDH) release as a measure of necrosis. The effects of SNAP treatment are shown in Figure 1a and TNF- $\alpha$ treatment in Figure $1 \mathrm{~b}$.

SNAP treatment exhibited a dose-dependent increase in apoptotic cell death with no significant increase in necrosis ( $P>0.05$ versus control) at all concentrations tested. SNAP $(0.1 \mathrm{mM})$ showed minimal apoptotic death $(15 \%$ Annexin V- and $8 \%$ TUNEL-positive cells) but as the dose of SNAP increased, apoptotic levels increased with $23 \%$
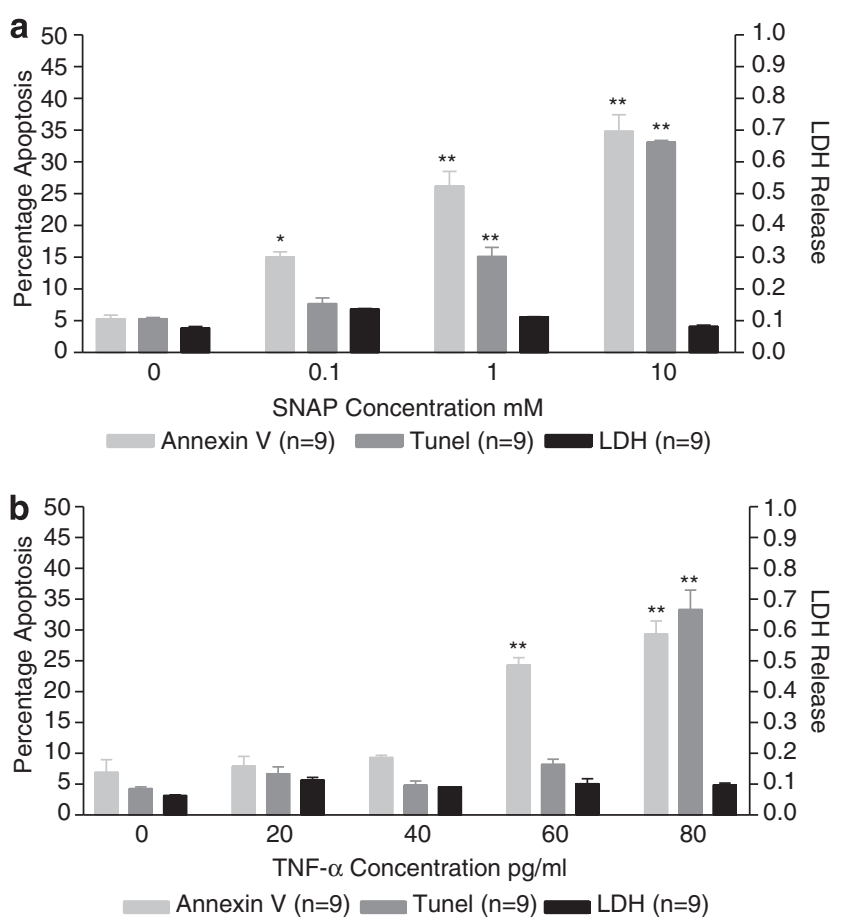

Figure 1 Apoptotic and necrotic chondrocyte cell death assessed as the percentage of Annexin V- and TUNEL-positive cells (apoptosis) and cellular LDH release (necrosis) following treatment of $\mathrm{C}$-20/A4 cells with increasing concentrations of SNAP (a) and TNF- $\alpha$ (b). ${ }^{*} P<0.05$. ${ }^{* *} P<0.01$ compared with control (untreated)

Annexin V-and 18\% TUNEL-positive cells $(P<0.01$ versus control) at $1 \mathrm{mM}$ and $35 \%$ Annexin $\mathrm{V}$ and $33 \%$ TUNELpositive cells $(P<0.01$ versus control) at $10 \mathrm{mM}$. Based on these data a concentration of $1 \mathrm{mM}$ SNAP was used for all subsequent experiments.

TNF- $\alpha$ treatment similarly showed a dose-dependent increase in apoptotic cell death, again with no significant increase in necrosis ( $P>0.05$ versus control) at all concentrations tested. Minimal apoptotic cell death was apparent at concentrations up to $40 \mathrm{pg} / \mathrm{ml} \quad(P>0.05$ versus control) but apoptotic cell death was observed at concentrations of $60 \mathrm{pg} / \mathrm{ml}$ and above with a significant $(P<0.01$ versus control $)$ increase to $24 \%$ Annexin V-positive cells. A small increase in TUNEL-positive cells was evident, but this was not statistically significant $(P>0.05$ versus control). $80 \mathrm{pg} / \mathrm{ml}$ TNF- $\alpha$ treatment resulted in a significant $(P<0.001$ versus control) increase in both Annexin V and TUNEL positivity (29\% and $33 \%$, respectively). Based on these data a concentration of $70 \mathrm{pg} / \mathrm{ml}$ TNF- $\alpha$ was used for all subsequent experiments.

The endogenous expression of Ucn and its receptors by C-20/A4 chondrocytes. Optimum annealing temperature and amplification cycle number (linear part of the amplification curve) were determined for reverse transcriptionPCR (RT-PCR) of Ucn and glyceraldehyde 3-phosphate dehydrogenase (GAPDH) in C-20/A4 chondrocytes (full data not shown, optimum conditions described in Table 1). Ucn and GAPDH expression were analyzed by agarose gel electrophoresis (Figure 2a) and quantified by densitometric analysis of the resulting PCR amplicons with Ucn expression 
Table 1 Sequences of primers used for PCR amplification of cDNA and predicted amplicon sizes

\begin{tabular}{|c|c|c|c|c|}
\hline Gene & Primer sequence $\left(5^{\prime} \rightarrow 3^{\prime}\right)$ & Expected product size (bp) & PCR protocol & Cycles \\
\hline $\begin{array}{l}\text { UCN } \\
\text { (Human) }\end{array}$ & $\begin{array}{l}\text { CAGGCGAGCGGCCGCG } \\
\text { CTTGCCCACCGAGTCGAAT }\end{array}$ & 146 & $94^{\circ} \mathrm{C} / 57^{\circ} \mathrm{C} / 72^{\circ} \mathrm{C}$ & 33 \\
\hline GAPDH & CCTGCTTCACCACCTTCTTG & 437 & $94^{\circ} \mathrm{C} / 58^{\circ} \mathrm{C} / 72^{\circ} \mathrm{C}$ & 30 \\
\hline $\begin{array}{l}\mathrm{CRH}^{-\mathrm{R}_{1}} \\
\text { (Human) }\end{array}$ & $\begin{array}{l}\text { ACAAACAATGGCTACCGGGA } \\
\text { GGACCACGAACCAGGTGGCG }\end{array}$ & $\begin{array}{l}280(\mathrm{R} 1 \alpha) \\
367(\mathrm{R} 1 \beta)\end{array}$ & $94^{\circ} \mathrm{C} / 58^{\circ} \mathrm{C} / 72^{\circ} \mathrm{C}$ & 45 \\
\hline $\begin{array}{l}\mathrm{CRH}-\mathrm{R}_{2} \\
\text { (Human) }\end{array}$ & $\begin{array}{l}\text { AGCCCATTTTGGATGACAAG } \\
\text { AGGTGGTGATGAGGTTCCAG }\end{array}$ & 180 & $94^{\circ} \mathrm{C} / 58^{\circ} \mathrm{C} / 72^{\circ} \mathrm{C}$ & 45 \\
\hline $\begin{array}{l}\mathrm{CRH}-\mathrm{R}_{2} \alpha \\
\text { (Human) }\end{array}$ & $\begin{array}{l}\text { TCCACAGCCTGCTGGAGGCC } \\
\text { CTCCAAGCATTCTCGATAGGC }\end{array}$ & 239 & $94^{\circ} \mathrm{C} / 58^{\circ} \mathrm{C} / 72^{\circ} \mathrm{C}$ & 45 \\
\hline $\begin{array}{l}\mathrm{CRH}-\mathrm{R}_{2} \beta \\
\text { (Human) }\end{array}$ & $\begin{array}{l}\text { CCTCCTCTACGTCCCACACC } \\
\text { CTCCAAGCATTCTCGATAGGC }\end{array}$ & 310 & $94^{\circ} \mathrm{C} / 58^{\circ} \mathrm{C} / 72^{\circ} \mathrm{C}$ & 45 \\
\hline $\begin{array}{l}\mathrm{CRH}-\mathrm{R}_{2 \gamma} \gamma \\
\text { (Human) }\end{array}$ & $\begin{array}{l}\text { TGGGAAGAGAGCCTTGGCC } \\
\text { CTCCAAGCATTCTCGATAGGC }\end{array}$ & 212 & $94^{\circ} \mathrm{C} / 58^{\circ} \mathrm{C} / 72^{\circ} \mathrm{C}$ & 45 \\
\hline
\end{tabular}
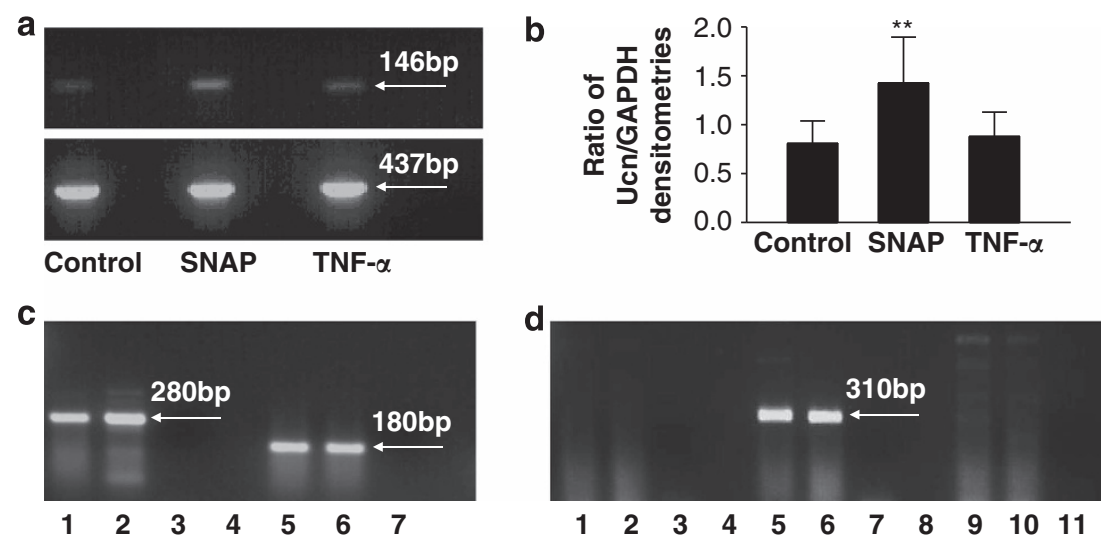

Figure 2 (a) RT-PCR analysis of Ucn (upper panel) and GAPDH (lower panel) expression in control (untreated) C-20/A4 chondrocytes and cells treated with $1 \mathrm{mM}$ SNAP and $70 \mathrm{pg} / \mathrm{ml}$ TNF- $\alpha$. Ucn and GAPDH amplicon sizes are indicated. (b) Ratio of Ucn/GAPDH expression in control (untreated) C-20/A4 chondrocytes and cells treated with $1 \mathrm{mM}$ SNAP and $70 \mathrm{pg} / \mathrm{ml}$ TNF- $\alpha$ as determined by densitometric analysis of PCR products shown in a. (c) RT-PCR analysis of CRFR subtype expression in C-20/A4 chondrocytes. Lanes 1 and $2=$ CRFR 1 product, lane $3=$ CRFR1-negative control, lanes 5 and $6=$ CRFR2 product, lane $7=$ CRFR2-negative control. CRFR amplicon sizes are indicated. (d) RT-PCR analysis of CRFR2 splice variant expression in C-20/A4 chondrocytes. Lanes 1 and $2=$ CRFR2 $\alpha$ PCR - no product, lane $3=$ CRFR2 $\alpha$-negative control, lanes 5 and $6=\mathrm{CRFR} 2 \beta$ PCR product, lane $7=\mathrm{CRFR} 2 \beta$-negative control, lanes 9 and $10=\mathrm{CRFR} 2 \gamma \mathrm{PCR}-$ no product, lane $11=\mathrm{CRFR} 2 \gamma$-negative control. CRFR $\beta$ amplicon size is indicated

'normalized' to GAPDH expression (Figure 2b). Basal expression of Ucn and GAPDH was determined in control/ untreated cells and the ratio of Ucn/GAPDH expression compared with that in cells treated with SNAP and TNF- $\alpha$. Figures $2 \mathrm{a}$ and $\mathrm{b}$ clearly indicate that SNAP treatment results in an increased expression of Ucn $(P<0.01$ versus control), whereas TNF- $\alpha$ treatment does not appreciably induce Ucn expression ( $P>0.05$ versus control).

Again, following the identification of optimum annealing temperatures and amplification cycle number for RT-PCR of the CRF receptors in C-20/A4 chondrocytes (full data not shown, optimum conditions described in Table 1), we have identified the expression of both CRFR1 and CRFR2 receptor subtypes in these cells. Specifically, we demonstrate the expression of CRFR $1 \alpha$ and CRFR $2 \beta$ subtypes, and the identities of the PCR products were confirmed by direct sequencing. Protein expression of both classes of receptor was confirmed by western blotting with antibodies specific for CRFR1 and CRFR2 (Figure 3).

Endogenous Ucn production is required for chondrocyte survival. In order to assess the importance
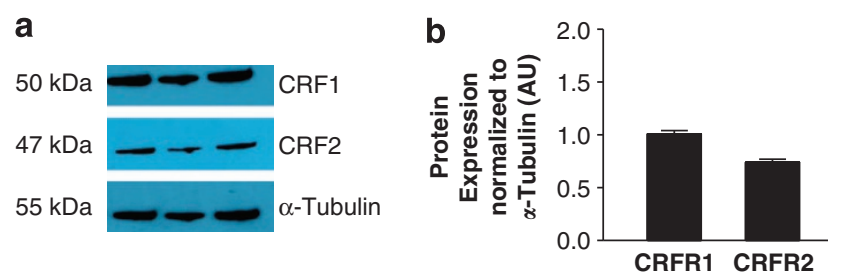

Figure 3 (a) Western-blot analysis of CRFR expression. CRFR1 and CRFR2 protein levels were determined using rabbit anti-CRFR1 and rabbit anti-CRFR2 monoclonal antibodies with a mouse anti- $\alpha$-tubulin monoclonal antibody used as a loading control. Bands with sizes corresponding to $50 \mathrm{kDa}$ (CRFR1), $47 \mathrm{kDa}$ (CRFR2) and $55 \mathrm{kDa}$ ( $\alpha$-tubulin) were detected. (b) Observed bands were quantified by densitometry and CRFR expression normalized to that of $\alpha$-tubulin. Data are presented as mean \pm S.E.M. of three independent experiments

of the endogenous, inducible Ucn expression demonstrated above, we performed receptor blocking and ligand depletion studies and determined the effects of these actions on C-20/A4 chondrocyte death in the absence of pro-apoptotic stimuli (Figure 4). Treatment with the non-selective CRFR antagonist $\alpha$-helical $\mathrm{CRH}_{(9-41)}$ alone $\left(10^{-8} \mathrm{M}\right)$ resulted in a significant $(P<0.01$ versus control) increase in apoptotic cell 


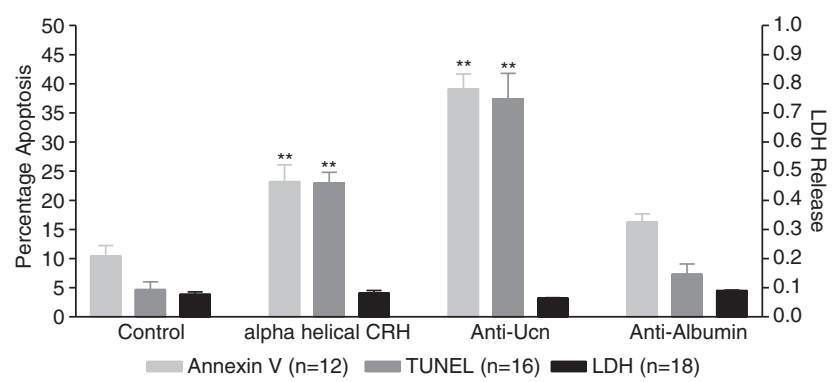

Figure 4 Cytoprotective effects of endogenous Ucn. Apoptotic and necrotic chondrocyte cell death assessed as the percentage of Annexin V-and TUNELpositive cells (apoptosis) and cellular LDH release (necrosis) following the treatment of $\mathrm{C}-20 / \mathrm{A} 4$ cells, with the $\mathrm{CRH}$ receptor antagonist $\alpha$-helical $\mathrm{CRH}$, anti-UCN antibody and anti-albumin antibody, ${ }^{* *} P<0.01$ compared with control

death (23\% Annexin V, 23\% TUNEL) with no significant increase in necrotic cell death as determined by LDH release. Ligand depletion studies with a specific anti-human Ucn antibody resulted in even greater increases in apoptotic cell death (37\% Annexin V, 33\% TUNEL; $P<0.01$ versus control), whereas treatment with an isotype control antibody directed against human albumin resulted in no significant increase in apoptosis as compared with the control. There was no significant increase in necrotic cell death following treatment with either antibody.

The addition of exogenous Ucn is chondroprotective against pro-apoptotic stimuli. Using the optimum concentrations of SNAP $(1 \mathrm{mM})$ and TNF- $\alpha(70 \mathrm{pg} / \mathrm{ml})$ as determined in Figure 1, C-20/A4 chondrocytes were treated with these stimuli, in conjunction with the addition of exogenous Ucn $\left(10^{-8} \mathrm{M}\right)$. Figure 5 demonstrates that the addition of concomitant Ucn ameliorates the apoptotic cell death induced by both SNAP and TNF- $\alpha$ but appears more effective against that induced by SNAP. Treatment with both Ucn and SNAP resulted in a significant reduction of apoptosis (14\% Annexin V and 10\% TUNEL) when compared with SNAP alone (23\% Annexin V and 19\% TUNEL; $P<0.01$ ). Treatment with Ucn and TNF- $\alpha$ resulted in a significant reduction in TUNEL positivity when compared with TNF- $\alpha$ alone (from $19 \%$ to $12 \%, P<0.05$ ) but no significant reduction in Annexin V-positive cells. In both the cases, the chondroprotective effect of Ucn is blocked by the addition of $\alpha$-helical $\mathrm{CRH}_{(9-41)}$ resulting in levels of cell death that are not significantly different to treatment with the pro-apoptotic stimuli alone.

\section{Discussion}

Given that chondrocyte apoptosis or 'chondroptosis' is thought to be one of the major mechanisms involved in the pathogenesis of $\mathrm{OA}$, and that we have previously shown Ucn to be cytoprotective in cardiac myocytes ${ }^{25}$ and neuronal cells, ${ }^{26}$ we sought to investigate a potential role for this peptide in chondrocyte responses to pro-apoptotic stimuli implicated in OA.

$\mathrm{NO}$ and the pro-inflammatory cytokine TNF- $\alpha$ have both been detected at elevated levels in osteoarthritic cartilage and both been implicated as possible contributors to chondrocyte death and cartilage damage. ${ }^{11,8}$ TNF- $\alpha$ is also involved in the amplification of the local inflammatory response within the joint. ${ }^{27}$ Initial data gathered in this study (Figures $1 \mathrm{a}$ and $\mathrm{b}$ ) confirm a dose-dependent increase in apoptotic cell death following treatment of C-20/A4 cells with these stimuli as determined by both Annexin $\mathrm{V}$ binding and TUNEL assays. No significant increase in necrotic cell death (as determined by cytoplasmic LDH release) was noted at all concentrations tested. Concentrations of $1 \mathrm{mM}$ SNAP (which releases approximately $60 \mathrm{nM}$ of free $\mathrm{NO}^{28}$ ) and $70 \mathrm{pg} / \mathrm{ml} \mathrm{TNF}-\alpha$ were selected for all further studies as these concentrations induced a consistent and easily quantifiable level of chondrocyte apoptosis with minimal necrosis. Furthermore, these concentrations are similar to those found within OA joints and similar to those used by others in studies with primary human chondrocytes. ${ }^{11,29,30}$

In order to establish the potential of the Ucn system as a chondroprotective mechanism, expression of Ucn and CRFR mRNA in C-20/A4 cells was first investigated in untreated, control cells where RT-PCR demonstrated constitutive expression of both Ucn and CRFRs (Figure 2a, lane 1 and Figure 2c, respectively) with the identity of the resulting amplicons confirmed by sequence analysis. Not only is the demonstration of Ucn expression in chondrocytes novel, these studies and the accompanying western blotting studies (Figure 3) also intriguingly demonstrated the expression of both CRFR1 and CRFR2 receptor subtypes in these cells (CRFR $1 \alpha$ and CRFR2 $\beta$ ), a phenomenon that, as far as we are aware, has not previously been reported. The identity of these receptor subtype variants further confirms that both subtypes are represented by an active splice-variant with CRFR1 $\alpha$ being the only active CRFR 1 isoform ${ }^{31}$ and CRFR2 $\beta$ being one of the three active forms of CRFR2 (CRFR2 $\alpha$, CRFR2 $\beta$ and CRFR2 $\gamma$ ). ${ }^{32}$ Furthermore, although CRFR2 $\alpha$ is the predominant CRFR2 isoform expressed in the human periphery, it has been shown through adenylate cyclase activation studies that Ucn and the other CRF-related peptides may preferentially activate the larger CRFR2 $\beta$ isoform over CRFR $2 \alpha$ and CRFR $2 \gamma,{ }^{33}$ despite there being no pharmacological differences in ligand binding. ${ }^{32}$ This may be explained by the fact that the CRFR $2 \alpha$ and CRFR2 $\gamma$ isoforms lack the $\mathrm{N}$-terminal domain encoded by exons 1 and 2 of the CRFR2 gene, an extracellular region thought to be important in ligand recognition and interaction. ${ }^{33}$ Having confirmed the expression of both Ucn and its receptors, we then studied the effects of pro-apoptotic insults on cellular expression of these components of the Ucn system. Although there was no significant variation in receptor expression following treatment with pro-apoptotic stimuli (data not shown), ligand expression was, however, significantly induced by SNAP, but not TNF- $\alpha$ treatment (Figure $2 a$, lanes 3 and 5 , respectively, and Figure $2 b$ ). Following normalization of the PCR data by expressing the data as a ratio of Ucn/ GAPDH densitometry readings, it becomes readily apparent that Ucn expression increases nearly twofold following exposure to SNAP ( $P<0.01$ versus control) yet there is no significant change following TNF- $\alpha$ exposure (Figure $2 b$ ). These data would suggest that the Ucn system is therefore likely to represent a constitutive chondroprotective mechanism but moreover that it may represent a mechanism specifically targeted toward protection against certain stimuli. 


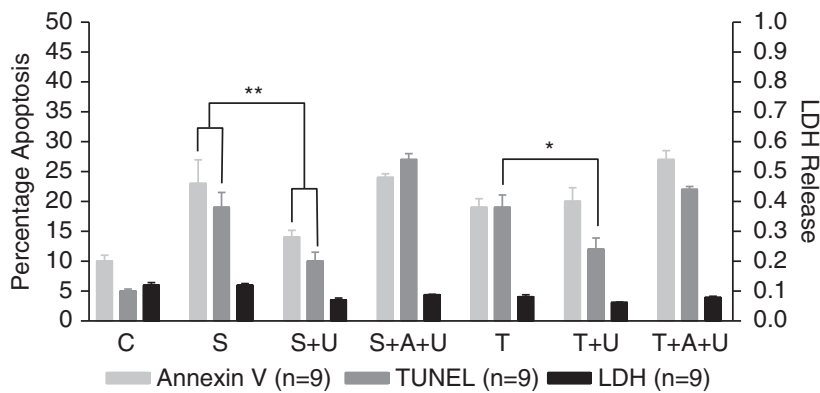

Figure 5 Cytoprotective effects of exogenous Ucn. Apoptotic and necrotic chondrocyte cell death assessed as the percentage of Annexin V-and TUNELpositive cells (apoptosis) and cellular LDH release (necrosis) following treatment of C-20/A4 cells with Ucn (U) administered concurrently with SNAP (S) or TNF- $\alpha(T)$ in the presence or absence of $\alpha$-helical CRH (A) ${ }^{*} P<0.05,{ }^{* *} P<0.01$ compared with control (C).

Following the demonstration of Ucn mRNA production by $\mathrm{C}-20 / \mathrm{A} 4$ cells the presence of functional endogenous Ucn production was confirmed by CRFR receptor blockade (by $\alpha$-helical $\mathrm{CRH}_{(9-41)}$, a competitive inhibitor of both CRFR1 and CRFR2 receptor subclasses) and the specific depletion of Ucn ligand released into the culture medium (using an Ucn-specific antibody). These experiments not only demonstrate the presence of functional Ucn peptide in these cells, but also suggest that the Ucn system represents an essential endogenous mediator of chondrocyte survival as both CRFR blockade and selective ligand depletion result in high levels of chondrocyte death, even in the absence of pro-apoptotic stimuli. The addition of isotype control antibody (anti-human albumin) did not result in any significant increase in chondrocyte apoptosis when compared with control cells (Figure 4).

In order to further characterize Ucn-mediated chondroprotection, and its possible selective nature, cytoprotection experiments were performed with the addition of exogenous Ucn, concomitant with SNAP and TNF- $\alpha$ treatment. As shown in Figure 5, co-treatment with SNAP and exogenous Ucn results in a significant decrease in the level of C-20/A4 apoptosis induced by SNAP treatment alone, protection that is again reversed by the addition of $\alpha$-helical $\mathrm{CRH}(9-41)$. When added in conjunction with TNF- $\alpha$, however, the chondroprotective effects of Ucn are much less evident. The TUNEL assay data reveal a small reduction in cell death but the Annexin $\mathrm{V}$ assay, however, does not show any significant difference when compared with TNF- $\alpha$ treatment alone. Taken together, these data would suggest that Ucn appears to principally confer cytoprotection against pro-apototic stimuli that induce cell death via the intrinsic/mitochondrial apoptotic pathway (e.g., NO), but is less effective against stimuli acting through the extrinsic/death receptor-mediated pathway (e.g., TNF- $\alpha$ ). These findings are in agreement with cardiac myocyte-derived data where Ucn was shown to prevent mitochondrial damage and inhibit lipid peroxidation resulting from oxidative stress. ${ }^{34-36}$

Using a stable, well-established chondrocyte cell line, this study has demonstrated critical roles for Ucn as both an essential chondrocyte survival signal and as a chondroprotective agent in the presence of pro-apoptotic stimuli. As with all studies involving cell lines, these observations should, and will be, confirmed in primary chondrocytes but these two characteristics ultimately represent a putative role for the Ucn system in preserving cartilage tissue. Furthermore, when coupled with our recently published data demonstrating a potent anti-resorbtive role for Ucn in osteoclasts, ${ }^{19}$ a wider role in bone metabolism and maintenance is suggested. Together, these data would suggest that $U \mathrm{cn}$, by preserving the ability to lay down new cartilage as well as reducing bone resorption, may have therapeutic potential in both osteoporosis and $O A$.

\section{Materials and Methods}

Cell culture. In vitro experiments were performed with the C-20/A4 human chondrocyte cell line ${ }^{37}$ cultured in a medium consisting of Dulbecco's modified Eagle's medium containing $1 \mathrm{~g} / \mathrm{l}$ glucose (Lonza, Wokingham, UK), supplemented with 10\% (v/v) fetal calf serum (FCS; Labtech International, Uckfield, UK), 1\% (v/v) L-glutamine and $1 \%(\mathrm{v} / \mathrm{v})$ penicillin/streptomycin (Lonza) at $37{ }^{\circ} \mathrm{C}, 5 \% \mathrm{CO}_{2}$. When confluent, cells were passaged by treatment with $\mathrm{Ca}^{2+}$ and $\mathrm{Mg}^{2+}$-free phosphate-buffered saline (Lonza), prewarmed to $37^{\circ} \mathrm{C}$ and used as required. Following passage, the chondrocyte cell suspension $\left(1 \times 10^{6} \mathrm{cells} / \mathrm{ml}\right)$ was transferred to six-well tissue culture plates and incubated for $24-48 \mathrm{~h}$ in the above medium to allow cells to reach $\sim 80 \%$ confluency. The cells were then 'serum starved' for $24 \mathrm{~h}$ by replacing the normal, $10 \%$ FCS growth medium with medium containing $1 \%$ FCS (all other components unchanged). The cultured cells were then re-supplied with fresh 1\% FCS medium (control) or treated with fresh $1 \%$ medium containing the stimuli/reagents detailed below for $6 \mathrm{~h}$, after which levels of cell death were determined.

Six-well plate cultures were treated with individual or combination treatments of: the NO donor SNAP (Calbiochem, Nottingham, UK), TNF- $\alpha$ (R\&D Systems, Abingdon, UK), the $\mathrm{CRH}$ antagonist $\alpha$ helical $\mathrm{CRH}_{(9-41)}\left(10^{-8} \mathrm{M}\right.$; Sigma-Aldrich, Gillingham, UK), rabbit anti-human Ucn antibody (100 $\mu \mathrm{g} / \mathrm{ml})$ and an isotype control (anti-human albumin; $100 \mu \mathrm{g} / \mathrm{ml}$; both Sigma-Aldrich) and the level of chondrocyte cell death compared.

Measurement of cell death. Control and treated C-20/A4 cultures were assessed for both apoptotic and necrotic cell death. Apoptosis was assessed by fluorescence microscopy by Annexin V binding (TACS Annexin V-FITC kit, R\&D systems) and by terminal deoxynucleotidyl transferase-mediated dUTP nick end labeling (TUNEL; in situ cell death detection kit, Roche diagnostics, Lewes, UK). Necrotic cell death was assessed by cytoplasmic LDH release (TOX 7 In Vitro Toxicology assay kit, Sigma, Poole, UK). All assays were performed according to the manufacturer's standard protocol.

RNA isolation and RT-PCR. Total RNA was isolated using Qiagen RNeasy Plus micro kit with gDNA eliminator columns to prevent genomic DNA contamination (Qiagen, Crawley, UK) according to the manufacturer's standard protocol. RNA purity and concentration were determined spectrophotometrically at 260 and $280 \mathrm{~nm}$ in an Eppendorf Biophotometer (Eppendorf, Cambridge UK) and RNA integrity verified by $1 \%$ agarose gel electrophoresis in tris(hydroxymethyl)aminomethane (Tris)-acetate-EDTA buffer followed by ethidium bromide $(200 \mathrm{ng} / \mathrm{ml})$ staining and visualization on a UV transilluminator.

cDNA was synthesized from $2 \mu \mathrm{g}$ of each RNA sample using the Omniscipt reverse transcriptase kit in the presence of an RNAse inhibitor, oligo dt primer and mixed dNTPs (all from Qiagen). RNA and oligo dt mixes were initially heated to $70^{\circ} \mathrm{C}$ for $10 \mathrm{~min}$ (to denature secondary RNA structures) after which the other components were added and the final mix incubated at $37^{\circ} \mathrm{C}$ for $1 \mathrm{~h}$.

PCR was performed to assess the expression of Ucn system components (Ucn, CRF-BP and CRFR) in C-20/A4 chondrocyte cells, using Qiagen Taq PCR Master Mix (Qiagen). The target sequences were amplified using sequence-specific oligonucleotide primers designed to amplify the transcript of interest along with GAPDH as an internal reference. Primer sequences and PCR conditions are given in Table 1. Temperature gradient PCR was performed on an Eppendorf Mastercycler gradient PCR machine (Eppendorf, Cambridge, UK) to determine optimum annealing temperatures for each of the primer pairs and the same machine used for all subsequent amplifications. Products were visualized on $2 \%(\mathrm{w} / \mathrm{v})$ agarose gel electrophoresis in Tris-acetate-EDTA buffer followed by ethidium bromide $(200 \mathrm{ng} / \mathrm{ml})$ staining and visualization on a UV transilluminator. 
Where appropriate, densitometric analysis was employed to qualify gene expression relevant to the GAPDH housekeeping gene. Amplicon identity was confirmed by sequence analysis performed by GACT Biotech Ltd. (London, UK).

Western blotting. C-20/A4 expression of CRFR1 and CRFR2 receptors was determined by western blotting as previously described. ${ }^{38,39}$ Following electrophoresis in a $10 \%$ SDS-polyacrylamide gel, proteins were transferred onto nylon membrane by electroblotting, blocked for $1 \mathrm{~h}$ in $5 \%$ non-fat milk solution in Tris-hydrochloric acid-buffered saline, pH 7.5 (TBS) containing $0.1 \%(\mathrm{v} / \mathrm{v})$ Tween-20 and then incubated with either specific anti-CRFR1 or anti-CRFR2 (1:1000 dilution SAB4500465 and SAB4500466, Sigma-Aldrich, Dorset, UK) rabbit antibodies in blocking solution. Blots were washed in TBS before the addition of a secondary goat anti-rabbit HRP-conjugated antibody $(1: 2000$ dilution) and specific antibody binding was detected by enhanced chemiluminescence (Pierce Biotechnology, Rockford, IL, USA). Following detection, bound antibodies were removed by incubating the membranes in $100 \mathrm{mM}$ glycinehydrochloric acid, $\mathrm{pH} 2.5$, for $30 \mathrm{~min}$ and the blot re-probed to detect $\alpha$-tubulin as described previously. ${ }^{38,39}$ Densitometry analysis was performed using Image $\mathrm{J}$ software (NIH, Bethesda, MD, USA).

Statistical analysis. Data values from the figures are expressed as mean \pm S.D. of $n$-independent experiments. All experiments were repeated at least nine times with the exception of the western blots, which were repeated three times. All data were subjected to ANOVA followed by Bonferroni's correction for post hoc $t$-tests where appropriate. Probabilities of $P \leq 0.05$ were considered statistically significant. Statistical tests were performed using Microsoft Excel or Prism GraphPad software as applicable.

\section{Conflict of Interest}

The authors declare no conflict of interest.

1. Buckwalter JA, Mankin HJ. Articular cartilage: tissue design and chondrocyte-matrix interactions. Instr Course Lect 1998; 47: 477-486.

2. Muir $\mathrm{H}$. The chondrocyte: architect of cartilage. Biomechanics, structure, function and molecular biology of cartilage matrix macromolecules. Bioesssay 1995; 17: 1039-1048.

3. Buckwalter JA, Mankin HJ. Articular cartilage. J Bone Joint Surg Am 1997; 79A: 600-632.

4. Kobayashi K, Healey RM, Coutts RD, Amiel D. Changes in chondrocyte density with age in human knees. Trans Orth Res Soc 2003; 49: 566.

5. Loeser RF. Aging and osteoarthritis: the role of chondrocyte senescence and aging changes in the cartilage matrix. Osteoarthr Cartil 2009; 17: 971-979.

6. Roach HI, Aigner T, Kouri JB. Chondroptosis: a variant of apoptotic cell death in chondrocytes. Apoptosis 2004; 15: 365-773.

7. Blanco FJ, Ochs RL, Schwartz H, Lotz M. Chondrocyte apoptosis induced by nitric oxide. Am J Pathol 1995; 146: 75-85.

8. Fernandes JC, Martel-Pelletier J, Pelletier JP. The role of cytokines in osteoarthritis pathophysiology. Biorheology 2002; 39: 237-246.

9. Kim J, Xu M, Xo R, Mates A, Wilson GL, Pearsall AW et al. Mitochondrial DNA damage is involved in apoptosis caused by pro-inflammatory cytokines in Human OA chondrocytes. Osteoarthr Cartil 2010; 18: 424-432.

10. Lotz M, Hashimoto S, Kühn K. Mechanisms of chondrocyte apoptosis. Osteoarthr Cartil 1999; 7: 389-391.

11. Farrell AJ, Blake DR, Palmer RMJ, Moncada S. Increased concentrations of nitrite in synovial fluid and serum samples suggest increased nitric oxide synthesis in rheumatic diseases. Ann Rheum Dis 1992; 51: 1219-1222.

12. Amin AR, Di Cesare PE, Vyas P, Attur M, Tzeng E, Billiar TR et al. The expression and regulation of nitric oxide synthase in human osteoarthritis-affected chondrocytes: evidence for up-regulated neuronal nitric oxide synthase. J Exp Med 1995; 182: 2097-2102.

13. Murrell GAC, Jang D, Williams RJ. Nitric Oxide activates metalloproteinase enzymes in articular cartilage. Biochem Biophys Res Commun 1995; 206: 15-21.

14. Pelletier J, Jovanovic D, Fernandes JC, Manning P, Connor JR, Currie MG et al. Reduction in the structural changes of experimental osteoarthritis by a nitric oxide inhibitor. Osteoarthr Cartil 1999; 7: 416-418.

15. Allen RT, Robertson CM, Harwood FL, Sasho T, Williams SK, Pomerleau AC et al. Characterization of mature versus aged rabbit articular cartilage: analysis of cell density, apoptosis-related gene expression and mechanisms controlling chondrocyte apoptosis. Osteoarthr Cartil 2004; 12: 917-923.
16. Kohno M, Kawahito Y, Tsubouchi Y, Hanshiramoto A, Yamada R, Inoue KI et al. Urocortin expression in synovium of patients with rheumatoid arthritis and osteoarthritis: relation to inflammatory activity. J Clin Endocrinol Metab 2001; 86: 4344-4352.

17. Gonzalez-Rey E, Chorny A, Varela N, O'Valle F, Delgado M. Therapeutic effect of Urocortin on collagen-induced Arthritis by down-regulation of Inflammatory and Th1 responses and induction of regulatory T cells. Arthritis Rheum 2007; 56: 531-543.

18. Lawrence KM, Latchman DS. The Urocortins: mechanism of cardioprotection and therapeutic potential. Mini Rev Med Chem 2006; 6: 1119-1126.

19. Combs CE, Fuller K, Kumar H, Albert AP, Pirianov G, McCormick J et al. Urocortin is a novel regulator of osteoclast differentiation and function through inhibition of a canonical transient receptor potential 1-like cation channel. J Endocrinol 2012; 212: 187-197.

20. Florio P, Rossi M, Sigurdarottir M, Ciarmela P, Luisi S, Vigano P et al. Paracrine regulation of myometrial function: interaction between progesterone and corticotropin-releasing factor (CRF) and Activin A. Steroids 2003; 68: 801-807.

21. Perrin $\mathrm{MH}$, Vale WW. Corticotropin releasing factor receptors and their ligand family. Ann NY Acad Sci 1999; 885: 312-328.

22. Grammatopoulos DK, Randeva HS, Levine JD, Katsanou ES, Hillhouse EW. Urocortin, but not corticotropin-releasing hormone (CRH), activates the mitogen-activated protein kinase signal transduction pathway in human pregnant myometrium: an affect mediated via $\mathrm{R} 1 \alpha$ and R2 $\beta$ CRH receptor subtypes and stimulation of Gq-proteins. Mol Endocrinol 2000; 14 : 2076-2091.

23. Fekete EM, Zorrilla EP. Physiology, pharmacology and therapeutic relevance of urocortins in mammals: Ancient CRF paralogs. Front Neuroendocrinol 2007; 28: 1-27.

24. Seasholtz AF, Valverde RA, Denver RJ. Corticotropin-releasing hormone-binding protein: biochemistry and function from fishes to mammals. J Endocrinol 2002; 175: 89-97.

25. Brar BK, Stephanou A, Okosi A, Lawrence KM, Knight RA, Marber MS et al. CRH-like peptides protect cardiac myocytes from lethal ischaemic injury. Mol Cell Endocrinol 1999; 158: 55-63.

26. Abuirmeileh A, Lever R, Kingsbury AE, Lees AJ, Locke IC, Knight RA et al. The corticotrophin releasing factor like peptide urocortin reverses key deficits in two rodent models of Parkinson's disease. Eur J Neurosci 2007; 26: 417-423.

27. Horton WE Jr., Feng L, Adams C. Chondrocyte apoptosis in development, aging and disease. Matrix Biol 1998; 17: 107-115.

28. Matthews JR, Botting CH, Panico M, Morris HR, Hay RT. Inhibition of NF-kappaB DNA binding by nitric oxide. Nucleic Acids Res 1996; 24: 2236-2242.

29. Hulejová H, Barešová V, Klézl Z, Polanská M, Adam M, Šenolt L. Increased level of cytokines and matrix metalloproteinases in osteoarthritic subchondral bone. Cytokine 2007; 38: 151-156.

30. Kühn K, Shikhman AR, Lotz M. Role of NO, reactive oxygen species and P38 MAP kinase in the regulation of human chondrocyte apoptosis. J Cell Physiol 2003; 197: 379-387.

31. Zmijewski MA, Slominski AT. Emerging role of alternative splicing of CRF1 receptor in CRF signaling. Acta Biochem Pol 2010; 57: 1-13.

32. Dautzenberg FM, Hauger RL. The CRF peptide family and their receptors: yet more partners discovered. Trends Pharmacol Sci 2002; 23: 71-77.

33. Grammatopoulos DK, Chrousos GP. Functional characteristics of $\mathrm{CRH}$ receptors and potential clinical applications of $\mathrm{CRH}$-receptor antagonists. Trends Endocrin Met 2002; 13: 436-444.

34. Lawrence KM, Townsend PA, Davidson SM, Carroll CJ, Eaton S, Hubank M et al. The cardioprotective effect of urocortin during ischaemia/ reperfusion involves the prevention of mitochondrial damage. Biochem Biophys Res Commun 2004; 321: 479-486.

35. Townsend PA, Davidson SM, Clarke SJ, Khaliulin I, Carroll CJ, Scarabelli TM et al. Urocortin prevents mitochondrial permeability transition in response to reperfusion injury indirectly by reducing oxidative stress. Am J Physiol Heart Circ Physiol 2007; 293: 928-938.

36. Barry SP, Lawrence KM, McCormick J, Soond SM, Hubank M, Eaton S et al. New targets of urocortin-mediated cardioprotection. J Mol Endocrinol 2010; 45: 69-85.

37. Goldring MB, Birkhead JR, Suen LF, Yamin R. Use of immortalized human chondrocytes in studies of IL-1-mediated gene expression. Arthritis Rheum 1993; 36: S49.

38. Getting SJ, Riffo-Vasquez Y, Pitchford S, Kaneva M, Grieco P, Page CP et al. A role for MC3R in modulating lung inflammation. Pulm Pharmacol Ther 2008; 21: 866-873.

39. Kaneva MK, Kerrigan MJ, Grieco P, Curley GP, Locke IC, Getting SJ.. Chondroprotective and anti-inflammatory role of melanocortin peptides in TNF- $\alpha$ activated human C-20/A4 chondrocytes. Br J Pharmacol 2012; 167: 67-79.

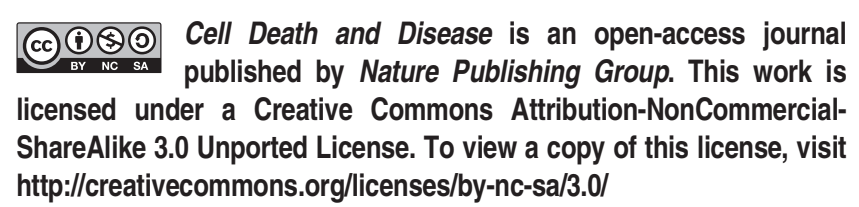

